\title{
The New Views of Competition System Reform of College Football League in China
}

\author{
FENG-Aimin \\ College of Physical Education, Dalian University, Dalian 116622,china
}

\begin{abstract}
Keywords: Competition system reform;Grading contest;Ascending and degrading system ;College Football League
\end{abstract}

Abstract. The healthy development of Chinese University Football League can effectively promote the development of the three League of high school, junior high school and primary school in our country. The College Football League should establish a more formal and perfect league. Study on the status of China college football league system, put forward a new idea of the reform of college football league system, namely to "establish a level system and the introduction of relegation system ", to build China's top level university tournament platform, promote the campus Football League to a more balanced development at a higher level.

\section{Introduction}

“The General Plan of Reform and Development of China's Football” that came into being in 2015 demonstrates the road for China football development. The campus football level 4 league is the ways and means for the implementation of the campus football activities. The College football level 4 league system which has been lasting 15 years among all the campus football levels is the most mature one. College football league is well known for its wide participation, high competitive level and great influence. It is also the most supported by the national sports association and the movement project, is the only officially recognized by the Chinese university sports association as a national format. College football league represents the highest level of level 4 football league, and its success can effectively promote the "high school, junior middle school and primary school" level 3 of the league.[1.2]. Despite the good policy support, the stable system, the reasonable operation mode and the secured funds as some important factors for the college league but there are still many practical problems. Because of the research and practical need I'd like to offer my view about the thoroughly reform of College football league competition system. that is : "to establish Demotion run system, football hierarchy" ensuring our country college football league to a higher development level and to send the talented football players to the national team .

\section{The new views about the reform of competition system for college football league in China}

College students' 11 man football league system reform. The football league reform Settings. (1)The qualification trial of the national college football league competition within the province

The qualification trial can be divided into two groups: "super group" and "campus group" according to the different levels of colleges and universities. The super group refers to colleges and universities with the right to recruit students with high level, the sports institutes; Campus group of colleges and universities refers to common colleges and vocational schools. The two groups use game-meeting system . They first compete within each province, then the winner of each province can participate in the national regional competition in the same year.

(2) College students' national football league regional competition. Super group can participate in the southern district, north district two division series, each district has 10-12 teams. Super group getting the first two places of south and north area will take part in next year's Minor league game. Campus groups can participate in the northeast, southeast, southwest, northwest four division series, 
each district has six to eight teams adopting in serie Minor league. The champion of each district of campus group will take part in next year's serie Minor league game.

(3) The national college students league in Minor league. Super group of college students in Minor league is composed of 12 teams, they are the first two places of south and north area last year, the 7th to 10th of serie Premier League last year,5th to 8th in Minor league .The game adopts game-meeting system. The first four winners in Minor league will take part in the next year national college students' league while the last four winners in Minor league will fall to the provincial league.

Campus group of college students in Minor league is composed of 16 teams, and they are the champion of each district out of the four districts last year, the 12th to 16th, in Serie Premier League last year, the 5th to 12 th in Minor league last year. The league adopts game-meeting system . The first four winners in Minor league will take part in serie Premier League in the next year national college students' league while the last four winners in Minor league will fall to the provincial league.

(4) the national college students' league. Super group of college students' league is composed of 12 teams, and they are the 1 st to 8th winners this season, the first four winners in Minor league last season. They fight for the national league rankings this year.The league uses game-meeting system and home and away and system. The last four winners in the league will fall to Minor league of the national college students league next year.

Campus group of college league is composed of 16 teams and they are from 1 st to 2 th of this year, the first four winners in Minor league last year. They fight for the national league rankings this year. The league uses game-meeting system and home and away and system. The last four winners in the league will fall to Minor league of the national college students league next year.

Football league schedule. (1) The provincial league: December - April next year

(2) The national regions: April - May yearly

(3) Minor league: May - June yearly

(4) National league: First division: Two stages, the first stage: May each year; the second stage:

Or

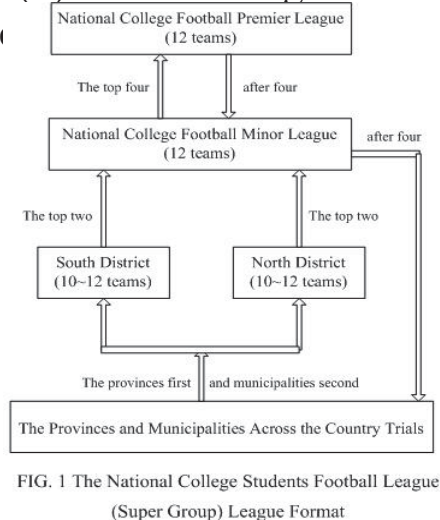

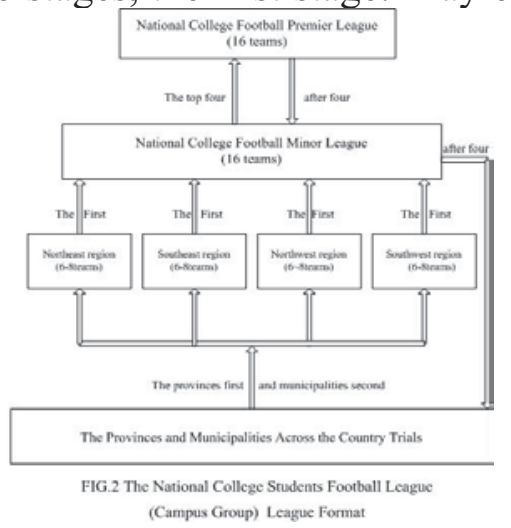

The system reform of college students football league concerning 5 players . league format Settings. (1) qualification trials of 5 players of the national college soccer league competition within the province.

All colleges and universities ' soccer teams have the right to join in the qualification trials within a province by adopting game-meeting system and the champion of each province will participate in the national regional competition in the same yea.

(2) The national soccer league regional competition of 5 players

The champion of each province will take part in the southern district, north district two division series. The first two teams of each district can participate in next year 5 players soccer game in Minor league.

(3) The national college soccer league of 5 players in Minor league

The national college soccer league of 5 players in Minor league consists of 12 teams, they are: the first two places in each region of south and north last year, from the 7 th to 10 th in the national college soccer league last year, the 5 th to 8 th in the S Minor league last year, adopting game-meeting system. The first four teams in Minor league will take part in the national college soccer league of 5 players, while the last four teams will fall to the provincial competition. 
(4) The national college soccer Premier League of 5 players

The national college soccer Premier League is composed of 12 teams, from the first to the 8th this year, the first four teams in Minor league last year. These teams fight for the national rank this year, adopting game-meeting system and home and away and system. The last four teams have to downgrade to participate in the national college soccer league of 5 players in Minor league.

The schedule arrangement for college soccer league of 5 players. (1)The competition within the province: From Dec. to April next year

(2) The national regions competition : From April to May each year.

(3) The league of Serie B:From May to June each year

(4)The national college soccer Premier League :two stages .The first stage:May of each year.The second stage: October of each year

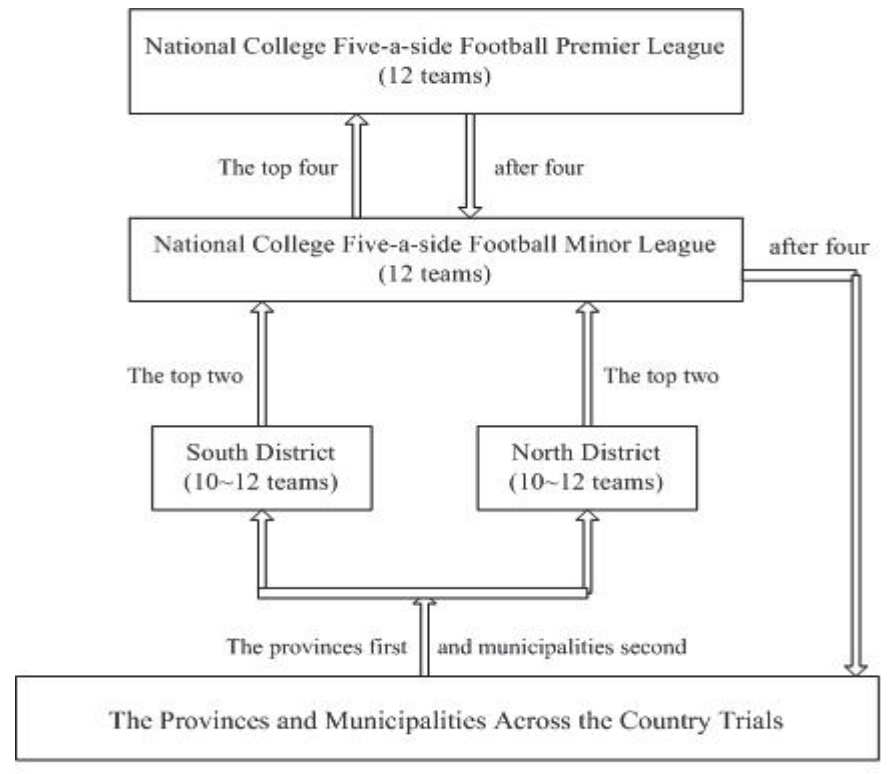

FIG.3 The National College Students Five-a-side Football League Format

\section{The obvious issues concerning the league system reform}

3.1 The influence of College football league on middle and primary schools' football league is not enough.

3.2 The Level of the football team in different places is uneven.

3.3 Financial issue.

3.4 The issue about the conflict during the match time .

3.5 lack of reward method.

\section{The conclusion}

College football league adopts Grading contest, Ascending and degrading system for strengthening the popularization and improving of the league, and it provides us with a new train of thought. At present he reforming of the competition system of college football league helps to popularize college football league in our country. Firstly it helps to perfect the college football league ; secondly high talented football players can be picked out and provide to the national team after high level competition; thirdly well organized college football league can set an example for primary school and secondary school to follow; fourthly it finds a better channel to higher school for the football players in primary and secondary school; fifthly it does good to the development of college football league and promotes the number and enthusiasm of participating teams ; sixthly it 
builds a higher, stronger platform for better development of college football teams. what I have proposed about the reform of college football league is based on principles of fair competition in order to promote spiritual civilization as well as high level league. What I have pursued is to push the college football league to the highest sports game on campus. Therefore it can contribute to the rapid development of China's football and has profound significance.

\section{Fund project}

Humanities and Social Science Research Project For 2015 of The Ministry of Education ( Item no: 15YJA890006)

\section{References}

[1]Wang Youming. Specialized in the research of college football league format in China [J]. Journal of chengdu sports college, 2009 (7) : 56-58.

[2]The Ministry of Education. The national youth campus football competition system construction plan [EB/OL]. HTTP: / / http://www. moe.edu.cn/.2015.05. 